\title{
Incidence of tuberculosis among HIV infected individuals on long term antiretroviral therapy in private healthcare sector in Pune, Western India
}

Ameet Dravid ${ }^{1,2,3^{*}}$ (D), Kartik Natarajan², Mahenderkumar Medisetty², Raviraj Gawali², Uma Mahajan ${ }^{4}$, Milind Kulkarni ${ }^{1}$, Chinmay Saraf ${ }^{5}$, Charuta Ghanekar ${ }^{6}$, Sachin Kore ${ }^{7}$, Niranjan Rathod ${ }^{8}$ and Mrudula Dravid ${ }^{9}$

\begin{abstract}
Background: Despite rapid scale up of antiretroviral therapy (ART), Tuberculosis (TB) remains the commonest opportunistic infection and cause of death among HIV infected individuals in resource limited settings like India. Incidence of TB in individuals on ART in private healthcare sector in India is infrequently studied.

Methods: This retrospective cohort study conducted between 1st March 2009 and 1st March 2017 aimed to evaluate rate of incident TB in individuals initiated on ART at 3 private sector ART clinics in Pune, India. Individuals more than 12 years of age with ART duration of atleast 6 months were included. Patients were classified as having prevalent TB if they had a TB episode within the year prior to ART initiation or if they developed TB within 6 months of starting ART. Individuals who were diagnosed with TB after 6 months of starting ART were classified as incident TB cases. A recurrent episode of TB after treatment completion or cure of prevalent TB was also regarded as incident TB. Patients were classified as definitive TB if Mycobacterium tuberculosis was grown in culture from a biological sample or a positive rapid molecular test. Patients were classified as probable TB if there was radiologic evidence of TB in absence of confirmatory culture or PCR.
\end{abstract}

Results: 1904 patients with a median duration of follow up on ART of 57 (IQR $=32.0,84.0)$ months were included. Of these, 182 developed incident TB (22\% definitive TB, 38\% recurrent cases). TB incidence at 6-12 months, 13-24 months, 25-60 months and $>60$ months of ART was 24.32, 5.46, 2.54 and 0.75 cases per 100 person years respectively. Current time updated CD4 count $<500$ cells $/ \mathrm{mm}^{3}(p<0.0001$ ), virologic failure on ART (adjusted Hazard Ratio (aHR): 3.05 (95\% Cl: 2.094, 4.454), $p<0.0001$ ) and receipt of ART without IPT (aHR: 8.24 (95\% Cl, 3.358, 20.204), $p<0.0001$ ) were associated with higher risk of incident TB.

Conclusion: Starting ART early in treatment naïve individuals, prompt detection of virologic failure on ART and providing IPT along with ART will be useful in reducing incident TB. Efforts from private sector are crucial in achieving Sustainable Development Goals set by Government of India and attaining the vision of a TB free India.

Keywords: Incident tuberculosis, HIV, India, Private healthcare sector, Antiretroviral therapy, Isoniazid preventive therapy

\footnotetext{
* Correspondence: ameet.dravid@gmail.com

${ }^{1}$ Department of Medicine, Ruby Hall Clinic, Pune, Maharashtra, India

2Department of Medicine, Poona Hospital and Research Centre, Pune,

Maharashtra, India

Full list of author information is available at the end of the article
}

(c) The Author(s). 2019 Open Access This article is distributed under the terms of the Creative Commons Attribution 4.0 International License (http://creativecommons.org/licenses/by/4.0/), which permits unrestricted use, distribution, and reproduction in any medium, provided you give appropriate credit to the original author(s) and the source, provide a link to the Creative Commons license, and indicate if changes were made. The Creative Commons Public Domain Dedication waiver (http://creativecommons.org/publicdomain/zero/1.0/) applies to the data made available in this article, unless otherwise stated. 


\section{Background}

Tuberculosis (TB) is a major global public health problem. In 2016, 10.4 million cases of TB were reported to World Health Organization (WHO) worldwide. India accounts for one fourth (2.8 million cases) of global TB burden [1]. Approximately 0.5 million Indians die annually because of TB $[2,3]$. In addition, there are more than a million cases of TB each year which escape surveillance and are not notified to public health authorities in India. Majority of these individuals seek care in the private healthcare sector where they are not properly diagnosed and treated [2, 3]. HIV infection remains a known risk factor for development of $\mathrm{TB}$ and a key component for resurgence of incident TB in low and middle income countries like India [1, 4]. Approximately $5 \%$ of the incident TB cases in India have co-morbidity with HIV [2, 3]. An estimated 87,000 HIV associated TB cases were reported in India in 2016 and 12,000 patients died among them $[2,3]$.

Interventions to reduce $\mathrm{HIV}$ associated $\mathrm{TB}$ include antiretroviral therapy (ART), intensified TB case finding, isoniazid preventive therapy (IPT) and infection control. The use of ART reduces the risk of developing TB by 70-90\% [5, 6]. As of 2017, 1.1 million individuals were on ART in India [7]. Although, addition of Isoniazid preventive therapy (IPT) to ART is shown to further reduce TB incidence [8], only $15 \%$ of eligible patients in India were on IPT as of 2017 [2, 3].

Modeling studies have suggested that expansion of ART coverage, improvement in TB diagnosis and treatment can help in drastic reduction in TB incidence and mortality [9]. However, cohort studies across regions do not share the same enthusiasm. They have shown high initial rates of TB in the first year of starting ART followed by gradual time-dependent reduction and stabilization above the estimated background population rate [10-24]. In addition, long term data on ART associated TB is limited. Median follow-up on ART in cohort studies rarely exceeds 2 years [4, 10, 11, 14, 20, 23]. As a result, calculation of long-term TB incidence rate is hampered due to small number of participants and events [20].

Incidence of TB among HIV infected individuals on ART in India is infrequently studied $[25,26]$, especially in the private healthcare sector which caters to almost $50 \%$ of overall TB cases [27]. Impact of ART related CD4 count recovery and virologic status on TB incidence has also not been well studied $[25,26]$. Our study was aimed to calculate the rate of incident $\mathrm{TB}$ (incident $\mathrm{TB}>6$ months after starting ART) in HIV infected patients on ART in a private sector healthcare setting in Pune, Western India and to study risk factors associated with it.

\section{Methods}

\section{Study setting}

This retrospective cohort study was conducted at private sector ART clinics in three tertiary level hospitals
(Ruby Hall Clinic, Poona Hospital and Noble Hospital) in Pune, Western India. Pune is located in state of Maharashtra which has the highest estimated number of people living with HIV (0.33 million, IQR - 0.25-0.43 million) in India [7] and has an annual TB notification rate of $>150$ cases per 100,000 people per year [2, 3].

These three private hospitals provide clinical care, diagnostic and treatment services to HIV infected individuals in the state of Maharashtra at a subsidized cost. Patients are referred from primary care physicians, private practitioners of alternative medical systems, antenatal clinics and TB clinics. Patient data, including demographic, clinical, laboratory and treatment are entered into an electronic database (Livehealth software solutions, Pune, India).

\section{Data collection and patient characteristics}

All patients $>12$ years of age who had registered into the ART program between 1st March 2009 and 1st March 2017, initiated ART and completed atleast 6 months of follow up were included. Individuals who were nonnaïve to ART at enrollment due to transfer in from another service were excluded. Baseline demographic data like age, gender, weight, hepatitis B co-infection, prevalent $\mathrm{TB}$, co-morbidities like diabetes mellitus (DM), CD4 count (FACS Count, Becton Dickinson, Franklin Lakes, NJ, USA), addictions and hemoglobin $(\mathrm{Hb})$ were collected from the database. CD4 count and Plasma HIV-1 viral load (NucliSENS Easy Q real-time nucleic acid sequence-based amplification (NASBA), BioMérieux ${ }^{\oplus}$, France, detection limit - 20 to 10,000,000 copies $/ \mathrm{ml}$ ) values, which were done 6 months after ART start and yearly thereafter were also collected. Details of ART regimens and duration of ART was recorded for all patients. WHO and Indian National AIDS control organization (NACO) guidelines [28, 29] were followed for starting first line ART and switch to second line or third line ART in our cohort.

\section{Ethics approval and consent to participate}

Access to raw data for clinical research was approved by Institutional review board (IRB) of all three hospitals (Ruby Hall Clinic, Poona Hospital and Noble Hospital).

\section{Tuberculosis screening and diagnosis}

From March 2009 to March 2011, a symptom screen consisting of fever of any duration, cough for $>2$ weeks, night sweats, weight loss of $>10 \%$, chest pain, hemoptysis and no response to outpatient antibiotic therapy was used to investigate for $\mathrm{TB}$ at baseline and every follow up visit [30]. Since March 2011, WHO symptom score (weight loss, fever, night sweats, and cough of any duration) was used for TB screening as a standard of care at all 3 hospitals [8]. Individuals with 
positive symptom score were investigated by radiologic (X ray chest, ultrasound of abdomen or Computerized tomography (CT) scan of thorax, abdomen and pelvis) and/or laboratory (Ziehl Nelson staining of biological samples) methods. TB confirmation was done by automated liquid TB culture (Mycobacterial growth indicator tubes, MGIT 960, Becton Dickinson, Sparks, Maryland, USA) or Cartridge based Nucleic acid Amplification test (CB-NAAT, Xpert MTB/RIF, Cepheid, USA) or TB line probe assay (LPA, Hain Lifesciences, Germany). Patients were classified as definitive TB if Mycobacterium tuberculosis was grown in culture from a specimen taken from patient (sputum, pus, biopsied tissue, etc.) or a positive TB CB-NAAT or positive TB LPA. Patients were classified as probable $\mathrm{TB}$ if there was radiologic evidence of TB or evidence of acid-fast bacilli (AFB) on Zn stain in absence of confirmatory culture or PCR.

\section{Definition of prevalent TB and incident TB}

Patients were classified as having prevalent TB if they had a TB episode within the year prior to ART initiation or if they already were on TB treatment when ART was started. Patients developing TB within 6 months of starting ART (early incident TB) were also classified as prevalent TB. Patients who had no history of prevalent $\mathrm{TB}$ and were diagnosed to have tuberculosis $>6$ months after starting ART were classified as having incident TB. A recurrent episode of $\mathrm{TB}$ after treatment completion or cure of baseline prevalent TB was also regarded as incident TB. Upon diagnosis of prevalent or incident TB, TB type (Extrapulmonary (EPTB) or pulmonary (PTB)) [31], date of TB treatment initiation and completion and TB drug susceptibility testing (DST) results were recorded. All cases of TB were treated as per latest TB treatment guidelines [32, 33].

\section{Use of ART with IPT}

After publication of 2011 WHO IPT guidelines [8], a subset of patients was initiated on IPT in addition to ART after excluding active TB. IPT was prescribed for 6 months irrespective of Tuberculin skin test (TST) status. Data of patients taking ART plus IPT as opposed to ART alone was recorded.

\section{Statistical methods}

Continuous variables were summarized using median and interquartile range (IQR), while categorical variables were summarized using frequency and percentages. Continuous variables were compared using a median test. Categorical variables were compared using Chisquare test and Fishers' exact test. TB incidence rate was defined as number of TB cases occurring per 100 person years after ART initiation. Duration of ART was calculated from date of ART initiation to development of first episode of incident TB, death of patient, lost to follow up (no clinic visits for more than 6 months) or censoring of observations on 1st March 2018. Person time accrued on ART during concomitant treatment of prevalent TB was excluded from denominator while calculating TB incidence rates.

Baseline and Time dependent risk factors associated with incident TB were identified by univariate and multivariate Cox proportional hazard model. Baseline risk factors considered were age ( $\leq 40$ years or $>40$ years), gender, prevalent TB, pre-ART CD 4 count $(C D 4 \leq 200$ and $>200)$, addictions and hemoglobin $(\mathrm{Hb}<10 \mathrm{~g} / \mathrm{dl}$ or $\geq 10 \mathrm{~g} / \mathrm{dl}$ ). Time dependent risk factors included were current time updated CD4 count, virologic status on ART (virologically suppressed (VS) or virologic failure (VF)) and use of ART with IPT. All data was analyzed by STATA version 12.0.

\section{Results}

A total of 1904 HIV infected individuals (34.4\% females) contributed to 9816.1 person years of follow up on ART (Fig. 1). Median age was 40 years $(\mathrm{IQR}=33.0,46.0)$ and median CD4 count prior to ART initiation was 173 $(\mathrm{IQR}=83.0,255.0)$ cells $/ \mathrm{mm}^{3}$. CD4 count prior to ART initiation was less than 50 cells $/ \mathrm{mm}^{3}$ in $14.1 \%$ patients. Hepatitis B surface antigen (HBsAg) was positive in $2.7 \%$ patients and $4.4 \%$ had baseline diabetes. Median duration of follow-up since HIV diagnosis was 62 (IQR = 36.0, 92.0) months and median duration of follow up on ART was 57 (IQR $=32.0,84.0)$ months. One thousand four hundred and eighty-two (77.8\%) and 413 (21.7\%) patients were on first line and second line ART regimens respectively. First line ART regimens comprised of 2 nucleoside reverse transcriptase inhibitors (NRTI) plus 1 non-nucleoside reverse transcriptase inhibitor (NNRTI)). Second line ART regimens contained 2 NRTI plus 1 ritonavir boosted protease inhibitor (PI) or 1 boosted PI with 1 integrase inhibitor. Tenofovir with Emtricitabine was the most commonly used NRTI backbone. Efavirenz was the most common NNRTI and Ritonavir boosted Atazanavir (ATV/r) was the most common PI used in our cohort. Virologic suppression (VS) was seen in $84.4 \%$ patients (plasma viral load (pVL) $<1000$ copies/ml) while virologic failure (VF, pVL > 1000 copies $/ \mathrm{ml}$ ) was seen in $15.6 \%$ patients at the time of latest plasma viral load estimation. At the end of the study period, $38.6 \%$ patients had reached a CD4 count threshold of $>500$ cells $/ \mathrm{mm}^{3}$. Of the total cohort, 18.8\% (358/1904) were prescribed IPT with ART.

\section{Baseline prevalent TB}

Baseline prevalent TB was seen amongst 33.5\% (637/1904) patients in our cohort. Of these, $80.7 \%$ had EPTB while 19.3\% had PTB. Male patients were 2 times more likely to have baseline TB than females $(p<0.0001)$. 


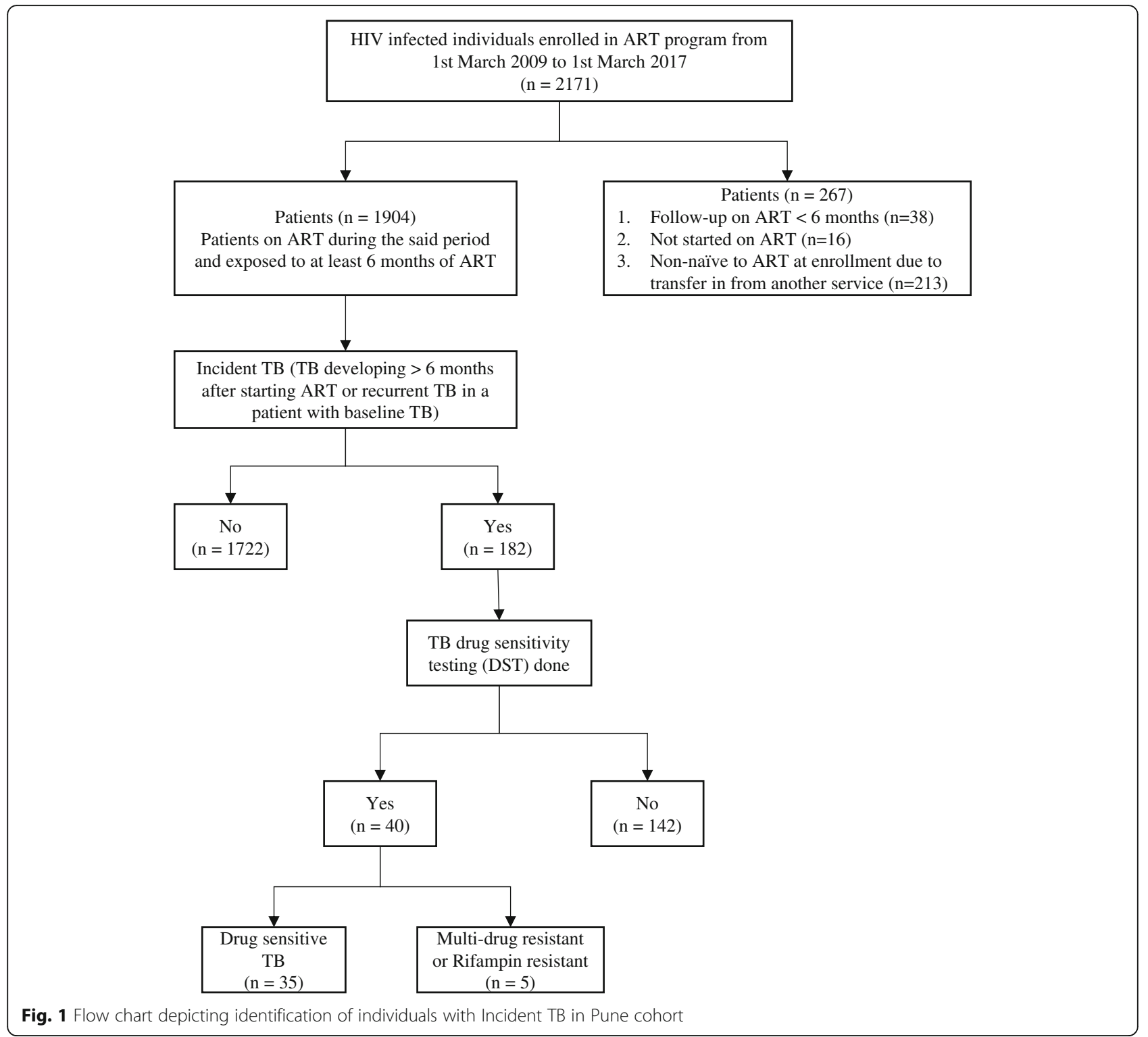

Median age of individuals with prevalent TB was 40 years $(\mathrm{IQR}=34.0,46.0)$ and median $\mathrm{CD} 4$ count at ART initiation was $108(\mathrm{IQR}=58.0,182.0) \mathrm{cells} / \mathrm{mm}^{3}$. Baseline prevalent TB was seen in 52, 12 and $6.3 \%$ patients with pre-ART CD4 counts $\leq 50,51-200$ and 201-500 cells $/ \mathrm{mm}^{3}$ respectively. Patients with prevalent TB had higher tobacco $(p<0.0001)$ and alcohol addiction $(p<0.0001)$, lower $\mathrm{Hb}(p<0.0001)$ and lower CD4 count at ART initiation $(p<0.0001)$ as compared to those without prevalent TB (Tables 1 and 2). Patients with prevalent $\mathrm{TB}$ had lower time updated $\mathrm{CD} 4$ count and higher incidence of VF on ART compared to patients without prevalent TB $(p<0.0001$, Table 2).

Incident TB was detected in 9.6\% (182/1904) patients (27.5\% females). Of the total incident cases, $73.9 \%$ patients had EPTB while $26.1 \%$ had PTB. Median age of individuals developing incident $\mathrm{TB}$ was $39 \mathrm{yrs}$. (IQR = 33.0, 46.0) and median CD4 count at ART initiation was $142(\mathrm{IQR}=78.0,198.0)$ cells $/ \mathrm{mm}^{3}$. Median CD4 count at the time of incident $\mathrm{TB}$ diagnosis was 156 (IQR $=68.0$, 314.0) cells $/ \mathrm{mm}^{3}$. Incidence rate for TB was 1.85 cases (95\% CI: $1.604-2.144$ ) per 100 person years. Median time to development of incident TB was $39(\mathrm{IQR}=16.0$, 68.0) months. Of all the patients with incident TB, 69 (37.9\%) had a history of prevalent TB. Median time interval between end of prevalent $\mathrm{TB}$ and diagnosis of incident $\mathrm{TB}$ was 38 months $(\mathrm{IQR}=16.0,66.0)$. The rate of incident TB was higher in patients with prevalent TB as compared to those without prevalent TB (2.11 (95\% CI: $1.666-2.671$ ) and 1.73 episodes (95\% CI: $1.436-$ 2.076) per 100 person years respectively, $p=0.181$, Table 3). 
Table 1 Baseline demographic data of patients in cohort

\begin{tabular}{|c|c|c|c|c|}
\hline \multirow[t]{2}{*}{ Characteristics } & \multirow{2}{*}{$\begin{array}{l}\text { Total patients } \\
(n=1904)\end{array}$} & \multicolumn{2}{|c|}{ Prevalent TB at baseline } & \multirow[t]{2}{*}{$p$-value } \\
\hline & & No & Yes & \\
\hline Total patients, $n(\%)$ & $1904(100 \%)$ & $1267(66.5 \%)$ & $637(33.5 \%)$ & \\
\hline Age (years), Median (IQR) † & $40(33.0,46.0)$ & $40(32.0,47.0)$ & $40(34.0,46.0)$ & 0.491 \\
\hline \multicolumn{2}{|l|}{ Gender, $n(\%)$} & & & $<0.0001$ \\
\hline Female & $654(34.4 \%)$ & $507(77.5 \%)$ & 147 (22.5\%) & \\
\hline Male & $1250(65.6 \%)$ & $760(60.8 \%)$ & $490(39.2 \%)$ & \\
\hline \multicolumn{2}{|l|}{ Ever Smoker, $n(\%)$} & & & 0.067 \\
\hline Yes & $221(11.6 \%)$ & $135(61.1 \%)$ & $86(38.9 \%)$ & \\
\hline No & $1683(88.4 \%)$ & $1132(67.3 \%)$ & $551(32.7 \%)$ & \\
\hline \multicolumn{2}{|l|}{ Ever Tobacco user, $n(\%)$} & & & $<0.0001$ \\
\hline Yes & $840(44.1 \%)$ & $482(57.4 \%)$ & $358(42.6 \%)$ & \\
\hline No & 1064 (55.9\%) & 785 (73.8\%) & $279(26.2 \%)$ & \\
\hline \multicolumn{2}{|l|}{ Ever consumed Alcohol, $n$ (\%) } & & & $<0.0001$ \\
\hline Yes & $642(33.7 \%)$ & $376(58.6 \%)$ & $266(41.4 \%)$ & \\
\hline No & $1262(66.3 \%)$ & $891(70.6 \%)$ & $371(29.4 \%)$ & \\
\hline \multicolumn{2}{|l|}{ Hepatitis B positive, $n(\%)$} & & & 0.074 \\
\hline Yes & $51(2.7 \%)$ & $28(54.9 \%)$ & $23(45.1 \%)$ & \\
\hline No & $1853(97.3 \%)$ & $1239(66.9 \%)$ & $614(33.1 \%)$ & \\
\hline \multicolumn{2}{|l|}{ Prior Diabetes Mellitus, $n$ (\%) } & & & 0.093 \\
\hline Yes & $84(4.4 \%)$ & $63(75.0 \%)$ & $21(25.0 \%)$ & \\
\hline No & 1820 (95.6\%) & $1204(66.2 \%)$ & 616 (33.9\%) & \\
\hline \multicolumn{2}{|c|}{ Haemoglobin at baseline $(\mathrm{g} / \mathrm{dl})(n=1592)^{\mathrm{a}}, n(\%)$} & & & $<0.0001$ \\
\hline$\leq 10$ & 388 (24.4\%) & $173(44.6 \%)$ & 215 (55.4\%) & \\
\hline$>10$ & 1204 (75.6\%) & 839 (69.7\%) & 365 (30.3\%) & \\
\hline
\end{tabular}

IQR Interquartile range, $T B$ tuberculosis. ${ }^{2}$ Hemoglobin data is not available for 312 patients

Of the incident TB cases, $21.9 \%$ (40/182) patients had culture or CB-NAAT confirmed TB while $78.1 \%$ (142/182) had probable TB. Thirty-three (33/182, 18.1\%) patients developed incident TB between 6 and 12 months of starting ART while 142 (81.9\%) developed it after 12 months of starting ART. Seventy-seven (42.3\%) patients with incident TB were virologically suppressed on ART while 105 (57.7\%) were virologic failures. Out of the 40 patients with definite TB, 35 had drug sensitive TB while 5 had Multi-drug resistant TB or Rifampicin mono-resistant TB on LPA. None of our patients who were subjected to LPA showed Isoniazid mono-resistant TB.

\section{ART duration and rate of incident TB}

TB incidence rate at 6-12 months, $13-24$ months and 2560 months of ART was 24.32, 5.46 and 2.54 cases per 100 person years respectively (Table 3 ). After 5 years on ART, there was a reduction in $\mathrm{TB}$ incidence rate to 0.75 cases per 100 person years.

Risk factors like age $(p=0.668)$, gender $(p=0.068)$ and baseline prevalent TB $(p=0.181)$ were not associated with incident TB. Baseline factors like CD4 count $\leq 200$ cells $/ \mathrm{mm}^{3}$ $(p<0.0001), \mathrm{Hb} \leq 10 \mathrm{~g} / \mathrm{dl}(p=0.001)$ and history of chewing tobacco $(p<0.0001)$ or consuming alcohol $(p=0.028)$ were associated with higher risk of incident TB on univariate analysis only (Table 4 ). Current time updated CD4 count $<500$ cells $/ \mathrm{mm}^{3}(p<0.0001)$, virologic failure on ART (aHR: 3.05 (95\% CI: 2.094, 4.454), $p<0.0001$ ) and receipt of ART without IPT (aHR: 8.24 (95\% CI: 3.358, 20.204), $p<0.0001$ ) were associated with higher risk of incident TB on univariate and multivariate Cox regression analysis (Table 4).

\section{Discussion}

India's vast, heterogeneous and unregulated private sector is plagued by poor diagnostic practices for TB leading to diagnostic delay, inadequate $\mathrm{TB}$ treatment regimens due to prescription errors, high rates of treatment non-completion due to poor adherence counseling and low notification rates to public health authorities [27, 34-36]. Despite these drawbacks, private healthcare sector caters to almost $50 \%$ of overall $\mathrm{TB}$ cases in India 
Table 2 Antiretroviral therapy data of patients in cohort

\begin{tabular}{|c|c|c|c|c|}
\hline \multirow[t]{2}{*}{ Characteristics } & \multirow{2}{*}{$\begin{array}{l}\text { Total patients } \\
(n=1904)\end{array}$} & \multicolumn{2}{|c|}{ Prevalent TB at baseline } & \multirow[t]{2}{*}{$p$-value } \\
\hline & & No & Yes & \\
\hline Total patients, $n(\%)$ & $1904(100 \%)$ & $1267(66.5 \%)$ & $637(33.5 \%)$ & \\
\hline ART regimes $(n=1894)^{\mathrm{b}}, n(\%)$ & & & & 0.947 \\
\hline NNRTI based & $1482(78.2 \%)$ & $983(66.3 \%)$ & $499(33.7 \%)$ & \\
\hline PI based & $413(21.8 \%)$ & $275(66.5 \%)$ & $138(33.5 \%)$ & \\
\hline Duration since HIV diagnosis (Months), Median (IQR) ${ }^{a}$ & $62(36.0,92.0)$ & $61(34.0,92.0)$ & $64(36.0,94.0)$ & 0.231 \\
\hline Duration on ART (Months), Median (IQR) ${ }^{a}$ & $57(32.0,84.0)$ & $56(32.0,85.0)$ & $60(32.0,82.0)$ & 0.382 \\
\hline CD4 count at ART initiation, Median (IQR) ${ }^{a}$ & $173(83.0,255.0)$ & $197(112.0,297.0)$ & $108(58.0,182.0)$ & $<0.0001$ \\
\hline CD4 count NADIR, Median (IQR) ${ }^{\text {a }}$ & $146(72.0,235.0)$ & $183(88.0,277.0)$ & $88(49.0,165.0)$ & $<0.0001$ \\
\hline Current/updated CD4 count, Median (IQR) ${ }^{\text {a }}$ & $402(236,620)$ & $440(286,664)$ & $331(187,521)$ & $<0.0001$ \\
\hline Virologic condition on ART, $n$ (\%) & & & & $<0.0001$ \\
\hline Virologic failure (VF) & $297(15.6 \%)$ & $166(55.9 \%)$ & $131(44.1 \%)$ & \\
\hline Virologic suppression (VS) & 1607 (84.4\%) & $1101(68.5 \%)$ & $506(31.5 \%)$ & \\
\hline IPT on ART, $n(\%)$ & & & & 0.001 \\
\hline ART plus IPT given & $358(18.8 \%)$ & $264(73.7 \%)$ & $94(26.3 \%)$ & \\
\hline ART alone & $1546(81.2 \%)$ & $1003(64.9 \%)$ & $543(35.1 \%)$ & \\
\hline
\end{tabular}

$A R T$ antiretroviral therapy, IPT ionized preventive therapy, IQR interquartile range, NNRTI nonnucleoside reverse transcriptase inhibitor, $P I$ protease inhibitor, $T B$ tuberculosis. ${ }^{a}$ Median test, ${ }^{b}$ Integrase inhibitor based ART regimen was given to 10 patients

(private-sector average tuberculosis burden of 2.2 million cases in 2014) [27] and TB incidence studies in private sector are long overdue. To the best of our knowledge, this is the first report on incident TB amongst ART experienced HIV infected individuals from Indian private healthcare sector. All patients were attended to by qualified allopathic healthcare providers at all 3 hospitals. In our cohort, we observed a $9.6 \% 5$ year risk of developing incident TB on ART, compared to the $10 \%$ lifetime risk in HIV uninfected individuals [37].

\section{Comparison with TB incidence studies from India}

We found 2 studies which reported the occurrence of ART associated TB from the Indian public health sector with a follow-up period of 6 months to 4 years $[25,26]$. These studies observed an incidence rate of 2.4-2.83 cases per 100 person years for the entire follow-up period which is higher than that seen in our study (1.85 cases per 100 person years). Lower incidence of TB in our cohort compared to the 2 reported studies could be due to the availability of better preventive, diagnostic and treatment set-ups and strategies for controlling TB [23]. Lower incidence rate of TB could also be due to longer follow up on ART in our cohort. Drawbacks of these studies $[25,26]$ include limited follow up on ART, majority of incident TB cases occurring in first 6 months post ART, all patients with symptoms not actively investigated for TB, nonavailability of time updated CD4 count and viral load values and nonuse of culture or molecular methods for TB diagnosis. The strengths of our cohort include its large size, maintenance of electronic records of all patients, prolonged duration of follow-up (median of 5 years), annual CD4 count and $\mathrm{pVL}$ monitoring, intensive $\mathrm{TB}$ case finding by applying WHO symptom score at every clinic visit, data on use of IPT and ART and recording of treatment outcomes of patients on antitubercular therapy (ATT).

\section{Prevalent TB}

We demonstrated a baseline $\mathrm{TB}$ prevalence rate of $33.5 \%$ among patients initiating ART in our cohort which is higher than previous reports from other resource-limited settings $[4,12,38]$. Higher prevalence could be related to intensive TB case finding at baseline or due to inclusion of patients with early incident TB as prevalent TB. This was done to eliminate the bias which might arise if prevalent TB is erroneously recorded as early incident TB due to limitation of available diagnostic tests. Rarely, TB may be missed during baseline screening and patients are started on ART. They may develop unmasking TB immune reconstitution inflammatory syndrome (IRIS) within 3 months of starting ART [39] and be falsely counted as incident TB. Diagnosing asymptomatic or subclinical TB among treatment naïve HIV infected patients is indeed complex and challenging [40]. In our cohort, there was a higher prevalence of baseline TB among male patients. This might be due to higher prevalence of advanced HIV disease among males as compared to female patients (Baseline CD4 $<200$ cells $/ \mathrm{mm}^{3}, 66.74 \%$ versus $50.38 \%$ ). This finding was also seen in a recently published meta-analysis 
Table 3 Rate of Incident TB in entire cohort and subgroup analysis

\begin{tabular}{|c|c|c|c|c|}
\hline \multirow[t]{2}{*}{ Characteristics } & \multicolumn{2}{|l|}{$\begin{array}{l}\text { Entire Cohort } \\
(n=1904)\end{array}$} & \multicolumn{2}{|c|}{$\begin{array}{l}\text { Patients with NO baseline prevalent TB } \\
(n=1267)\end{array}$} \\
\hline & $\begin{array}{l}\text { Number of patients } \\
\text { (n) }\end{array}$ & $\begin{array}{l}\text { Incidence rate }(95 \% \mathrm{Cl}) \text { per } 100 \text { person } \\
\text { years }\end{array}$ & $\begin{array}{l}\text { Number of patients } \\
\text { (n) }\end{array}$ & $\begin{array}{l}\text { Incidence rate }(95 \% \\
\mathrm{Cl}) \\
\text { per } 100 \text { person years }\end{array}$ \\
\hline Total patients & 182 & $1.85(1.604,2.144)$ & 113 & $1.73(1.436,2.076)$ \\
\hline \multicolumn{5}{|l|}{ Age (years) } \\
\hline$\leq 40$ years & 100 & $1.83(1.502,2.223)$ & 63 & $1.75(1.363,2.233)$ \\
\hline$>40$ years & 82 & $1.89(1.521,2.344)$ & 50 & $1.71(1.292,2.249)$ \\
\hline \multicolumn{5}{|l|}{ Gender } \\
\hline Female & 50 & $1.49(1.132,1.971)$ & 35 & $1.34(0.961,1.865)$ \\
\hline Male & 132 & $2.04(1.721,2.421)$ & 78 & $1.98(1.589,2.478)$ \\
\hline \multicolumn{5}{|l|}{ History of prior TB at baseline } \\
\hline Yes & 69 & $2.11(1.666,2.671)$ & & \\
\hline No & 113 & $1.73(1.436,2.076)$ & & \\
\hline $\begin{array}{l}\text { Haemoglobin at baseline }(\mathrm{g} / \\
\mathrm{dl})\end{array}$ & $(n=156)$ & & $(n=88)$ & \\
\hline$\leq 10$ & 53 & $2.84(2.171,3.719)$ & 65 & $2.79(1.853,4.196)$ \\
\hline$>10$ & 103 & $1.58(1.304,1.919)$ & 23 & $1.43(1.125,1.830)$ \\
\hline \multicolumn{5}{|l|}{ Virologic status on ART } \\
\hline Virologic failure (VF) & 105 & $8.51(7.030,10.307)$ & 71 & $10.23(8.107,12.910)$ \\
\hline Virologic suppression (VS) & 77 & $0.90(0.717,1.122)$ & 42 & $0.72(0.530,0.972)$ \\
\hline \multicolumn{5}{|l|}{ IPT } \\
\hline ART plus IPT & 5 & $0.20(0.081,0.469)$ & 2 & $0.11(0.026,0.423)$ \\
\hline ART alone & 177 & $2.44(2.106,2.828)$ & 111 & $2.38(1.979,2.872)$ \\
\hline \multicolumn{5}{|l|}{ Duration of ART (months) } \\
\hline$\leq 12$ & 33 & $24.32(17.293,34.215)$ & 23 & $25.58(16.998,38.492)$ \\
\hline $13-36$ & 52 & $5.46(4.162,7.167)$ & 29 & $4.32(3.005,6.223)$ \\
\hline $37-60$ & 44 & $2.54(1.890,3.413)$ & 28 & $2.41(1.666,3.495)$ \\
\hline$>60$ & 53 & $0.75(0.579,0.992)$ & 33 & $0.72(0.507,1.004)$ \\
\hline \multicolumn{5}{|l|}{ Pre ART CD4 count (cells/mm3) } \\
\hline$\leq 50$ & 32 & $2.28(1.612,3.224)$ & 18 & $2.57(1.621,4.085)$ \\
\hline $51-200$ & 108 & $2.20(1.824,2.660)$ & 59 & $1.98(1.537,2.560)$ \\
\hline $201-500$ & 41 & $1.28(0.943,1.740)$ & 35 & $1.35(0.967,1.875)$ \\
\hline$>500$ & 1 & $0.32(0.045,2.303)$ & 1 & $0.36(0.052,2.625)$ \\
\hline \multicolumn{5}{|c|}{ Current/ updated CD4 count (cells/mm3) } \\
\hline$\leq 200$ & 107 & $7.36(6.090,8.896)$ & 65 & $8.35(6.548,10.648)$ \\
\hline $201-350$ & 36 & $1.75(1.265,2.432)$ & 22 & $1.64(1.078,2.486)$ \\
\hline $351-500$ & 20 & $1.03(0.667,1.602)$ & 12 & $0.97(0.552,1.711)$ \\
\hline$>500$ & 19 & $0.43(0.277,0.681)$ & 14 & $0.44(0.260,0.741)$ \\
\hline
\end{tabular}

ART antiretroviral therapy, IPT Isoniazid preventive therapy, $T B$ tuberculosis

where males were found to be at $73 \%$ higher risk of advanced HIV disease at first clinic visit as compared to females [41]. Prevalent TB was also more common among patients with pre-ART CD4+ count $<50$ cells $/ \mathrm{mm}^{3}$ and anemia at baseline.
Baseline CD4 count and incident TB

Severity of immune suppression at the time of ART initiation was associated with risk of incident TB on univariate Cox regression analysis. Compared to those starting ART at CD4 count $>200$ cells $/ \mathrm{mm}^{3}$, 
Table 4 Cox Proportional Hazard Model for identifying risk factors for incident TB

\begin{tabular}{|c|c|c|c|c|}
\hline \multirow[t]{2}{*}{ Characteristics } & \multicolumn{2}{|l|}{ Univariate analysis } & \multicolumn{2}{|l|}{$\underline{\text { Multivariate analysis }}$} \\
\hline & $\begin{array}{l}\text { Hazard ratio } \\
(95 \% \mathrm{Cl})\end{array}$ & $p$-value & $\begin{array}{l}\text { Adjusted Hazard ratio } \\
(95 \% \mathrm{Cl})\end{array}$ & $p$-value \\
\hline Age $>40$ years (Ref: $\leq 40$ years) & $1.07(0.794,1.432)$ & 0.668 & $1.01(0.746,1.375)$ & 0.935 \\
\hline Male (Ref: Female) & $1.36(0.978,1.877)$ & 0.068 & $0.96(0.616,1.495)$ & 0.855 \\
\hline Ever Tobacco user (Ref: not used tobacco) & $1.90(1.413,2.560)$ & $<0.0001$ & $1.08(0.737,1.584)$ & 0.690 \\
\hline Ever consumed Alcohol (Ref: not consume alcohol) & $1.39(1.036,1.866)$ & 0.028 & $1.10(0.770,1.572)$ & 0.599 \\
\hline History of baseline prevalent TB (Ref: No baseline prevalent TB) & $1.23(0.909,1.656)$ & 0.181 & & \\
\hline Haemoglobin at baseline $\leq 10 \mathrm{~g} / \mathrm{dl}(n=1592)(\text { Ref: }>10 \mathrm{~g} / \mathrm{dl})^{\mathrm{a}}$ & $1.80(1.290,2.504)$ & 0.001 & & \\
\hline Virologic failure on ART (VF)(Ref: Virologic success (VS)) & $9.51(7.078,12.786)$ & $<0.0001$ & $3.05(2.094,4.454)$ & $<0.0001$ \\
\hline ART alone (Ref: ART plus IPT) & $12.71(5.217,30.943)$ & $<0.0001$ & $8.24(3.358,20.204)$ & $<0.0001$ \\
\hline Pre ART CD4+ $\leq 200$ cells/mm3(Ref: > 200 cells/mm3) & $1.87(1.326,2.647)$ & $<0.0001$ & $1.18(0.816,1.714)$ & 0.377 \\
\hline \multicolumn{5}{|l|}{ Pre ART CD4+ (Ref: > 500 cells/mm3) } \\
\hline$\leq 50$ & $6.87(0.937,50.321)$ & 0.058 & & \\
\hline $51-200$ & $6.60(0.921,47.370)$ & 0.060 & & \\
\hline $201-500$ & $3.79(0.521,27.596)$ & 0.188 & & \\
\hline \multicolumn{5}{|l|}{ Current/updated CD4+ (Ref: > 500 cells/mm3) } \\
\hline$\leq 200$ & $17.60(10.783,28.716)$ & $<0.0001$ & $6.62(3.678,11.915)$ & $<0.0001$ \\
\hline $201-350$ & $4.19(2.401,7.313)$ & $<0.0001$ & $3.22(1.808,5.746)$ & $<0.0001$ \\
\hline $351-500$ & $2.43(1.297,4.555)$ & $<0.0001$ & $2.05(1.083,3.888)$ & 0.027 \\
\hline
\end{tabular}

$A R T$ antiretroviral therapy, IPT isoniazid preventive therapy, TB tuberculosis

${ }^{a}$ Hemoglobin data is not available for 312 patients, hence excluded from the multivariate analysis

patients with low pre-ART CD4 count $(\leq 200$ cells/ $\mathrm{mm}^{3}$ ) were almost twice as likely to develop incident TB (aHR: 1.87 (95\% CI: 1.326-2.647). Those patients starting ART at CD4> 500 cells $/ \mathrm{mm}^{3}$ had the lowest risk of incident TB $(0.32$ cases per 100 person years). These findings were similar to that seen in study conducted by Bock et al. [42] in which TB incidence after ART initiation was significantly lower among individuals starting ART at CD4 counts above 500 cells $/ \mathrm{mL}$.

\section{Time updated CD4 count and incident TB}

In addition, time updated CD4 count was associated with risk of incident $\mathrm{TB}$ on univariate and multivariate Cox regression analysis. Compared to patients with current time updated CD4 count $>500$ cells $/ \mathrm{mm}^{3}$, patients with current CD4 count $\leq 200,201-350$, and 351-500 cells $/ \mathrm{mm}^{3}$ were six times (aHR: 6.62 (95\% CI: $3.678,11.915), p<0.0001$ ), three times (aHR: 3.22 (95\% CI: $1.808,5.746), p<0.0001)$ and two times (aHR: 2.05 (95\% CI: 1.083, 3.888), $p=0.027$ ) more likely to develop incident TB respectively (Fig. 2). These findings were similar to those published by Van Rie et al. [4] and Lawn et al. [11] in which low time updated CD4 count was a risk factor for incident TB. After starting ART, CD4 count threshold of 500 cells $/ \mathrm{mm}^{3}$ has to be exceeded to minimize incident TB risk [11]. In our cohort, despite effective ART almost $60 \%$ of individuals did not achieve this threshold. As a result, TB specific immune response was not properly reconstituted, and patients remained at risk of incident TB. These findings further strengthen the recommendation by current ART guidelines $[28,29]$ to start ART early and attain near normal CD4 count.

\section{Virologic failure on ART and incident TB}

In our cohort, patients with virologic failure (VF) on ART ( $\mathrm{pVL}>1000$ copies $/ \mathrm{ml}$ ) were 3 times more likely to develop incident TB (aHR: 3.05 (95\% CI: 2.094, 4.454). This association is also seen in other cohort studies [20]. HIV replication despite effective ART leads to immune activation, increased $\mathrm{T}$ and $\mathrm{B}$ cell turnover, skewing of lymphocytes towards differentiated phenotypes and increased cellular senescence. In addition, regenerative capacity of immune cells is damaged. This leads to poor quality of humoral and cellular immune response to common antigens and increased susceptibility to opportunistic infections (OI) [43]. In the study by Kaplan et al., patients on ART having $\mathrm{pVL}>150,000$ copies/ml had 3 times higher risk of OI compared to patients with suppressed HIV replication ( $\mathrm{pVL}<400$ copies/ml) [44]. Amongst ART experienced patients in South Africa, those with $\mathrm{pVL}>10,000$ copies $/ \mathrm{ml}$ had a $41 \%$ greater risk of incident 


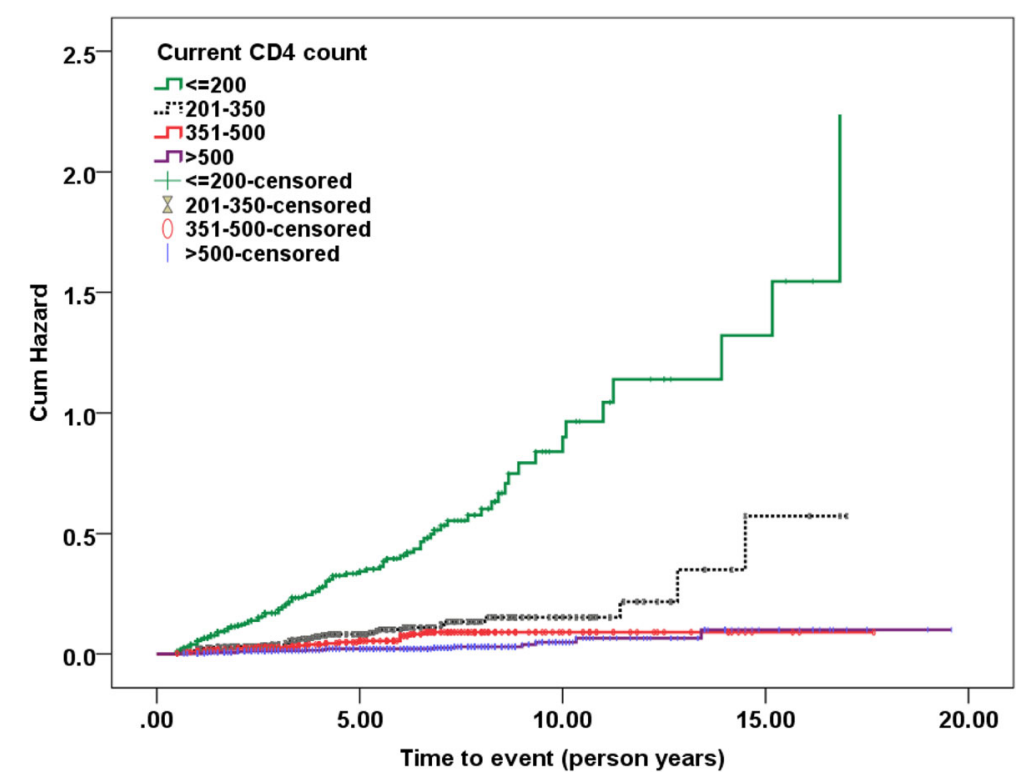

Fig. 2 Kaplan-Meier estimates for Incident TB by Current time updated CD4 count

TB as compared to patients with $\mathrm{pVL}<1000$ copies $/ \mathrm{ml}$ [45]. These findings emphasize the need for routine viral load testing for all patients on ART in India as per WHO [46] and NACO guidelines [47]. Early identification of virologic failure and immediate switch to fully active antiretroviral therapy can achieve viral re-suppression and reduce incidence of $\mathrm{TB}$.

\section{IPT and incident TB}

According to WHO, IPT should be administered to all HIV infected individuals residing in moderate to high TB incidence settings irrespective of their Tuberculin skin test (TST) status, once active TB is ruled out. IPT reduces the risk of developing incident TB by $33-67 \%$ for up to 48 months in such patients $[48,49]$. In a randomized, double blind placebo-controlled trial conducted by Rangaka et al., 12 months of IPT independently reduced the incidence of TB among patients concurrently on ART by 37\% [50]. Multiple cohort studies have also demonstrated the efficacy of ART plus IPT in preventing incident $\mathrm{TB}$ [51-53]. In our study, patients on ART alone were 8 times more likely to develop incident TB than patients on ART plus IPT (aHR: 8.24 (95\% CI: 3.358, 20.204). The rate of incident TB was 0.2 cases $/ 100$ person years and 2.44 cases/100 person years among patients exposed to ART plus IPT and ART alone respectively. Our data clearly suggests that IPT and ART have additive efficacy in preventing incident TB. Out of the 358 patients exposed to ART plus IPT, only 5 (1.39\%) developed incident TB. All episodes of incident TB occurred after discontinuation of IPT suggesting exogenous re-infection. The BOTUSA study comparing six-months versus 36-months of IPT in Botswana reported a $43 \%$ reduction in TB incidence with the longer regimen, an effect which was more striking among TSTpositive individuals. The efficacy of 6 month regimen seemed to wane about 200 days after IPT discontinuation. [54]. In another randomized controlled trial from India, TB incidence was lowered by 6 month Isoniazid plus ethambutol (6HE) based preventive regimen and 36 month IPT regimen by 65 and $78 \%$ respectively. TB incidence was $40 \%$ lower with longer regimen, but difference was not statistically significant [55]. Our findings support the use of longer term IPT in individuals on ART in India to prevent both, reactivation of latent $\mathrm{TB}$ and exogenous reinfection.

\section{ART duration and incident TB}

TB incidence rates in our cohort reduced from 24.32 cases per 100 person years at 6-12 months of ART to 0.75 cases per 100 person years after 5 years on ART. Decline in TB incidence may be related to the immune reconstitution and virologic suppression due to ART. Prior to starting ART, 61.1 and 4.5\% patients had CD4 count $<200$ and $>500$ cells $/ \mathrm{mm}^{3}$ respectively. After starting ART, only $18.95 \%$ patients had CD4 count $<200$ cells/ $\mathrm{mm}^{3}$ at study closure, while $38.9 \%$ patients had achieved CD4 count $>500$ cells $/ \mathrm{mm}^{3}$. Almost $85 \%$ patients had achieved virologic suppression. These findings were similar to that seen in other cohort studies from India [56]. Despite this reduction, TB incidence rates after 5 years of 
ART were higher than estimated community TB rate (150 cases per 100,000 population) $[2,3]$. We think that this phenomenon of high TB incidence may be due to multiple factors which include inability to reach a CD4 count threshold of $>500$ cells $/ \mathrm{mm}^{3}$ despite long term ART, impaired restoration of TB specific immunity [57], low usage of IPT in our cohort and high rate of TB re-infection $[58,59]$. The incidence rates observed are most likely due to a combination of these factors.

\section{Limitations of the study}

Our study has several limitations. First, as for all retrospective studies, some episodes of TB may be unreported leading to measurement bias and underestimation of prevalent and incident TB. Second, Body mass index (BMI) was not recorded in all patients in our cohort. Poor nutritional status $\left(\mathrm{BMI}<25 \mathrm{~kg} / \mathrm{m}^{2}\right)$ is a strong risk factor for incident TB [4]. Every unit increase in BMI leads to $13.8 \%$ reduction in TB incidence [60]. Third, person time spent in different time updated CD4 count strata and its association with risk of incident TB [20] was not calculated in our study. Fourth, in case of recurrent TB, we were unable to distinguish between recurrence due to exogenous re-infection or endogenous reactivation (relapse). Fifth, TB confirmation and Drug susceptibility testing (DST) by CB-NAAT or LPA was ascertained in only $22 \%$ of incident TB cases. The main reason for the same was high prevalence of EPTB in our cohort. DST like CBNAAT and LPA suffer from lower sensitivity in extrapulmonary samples [61]. In addition, widespread availability of DST in India started only in 2017 [3]. We believe that these numbers will definitely improve in the future. Authors also agree that a minority of these patients diagnosed with probable TB could be actually suffering from Non tuberculous Mycobacterial (NTM) infection which could present with similar radiologic features [62]. We estimate that the "non cases" or NTM infections would be $<5 \%$ of identified incident TB cases. Sixth, outcome data after initiation of TB treatment was not always readily available for complicated patients referred for hospitalization or for those that were lostto-follow-up.

\section{Conclusions}

Our study from the Indian private healthcare sector has shown a high rate of incident TB in patients on ART. It clearly demonstrates that despite ART scale-up and improving life expectancy of HIV positive patients in India, sizeable proportion of individuals remain susceptible to incident TB and will fall prey to it unless obstacles to TB prevention are removed. Starting ART early in treatment naïve individuals, close monitoring for incident $\mathrm{TB}$ in patients with low baseline and time updated CD4 count, routine virologic monitoring of all patients on ART and routine use of ART with IPT are important takeaways from our cohort study. Efforts from private sector are crucial in achieving the Sustainable Development Goals set by Government of India and attaining the vision of a TB free India.

\begin{abstract}
Abbreviations
aHR: adjusted Hazard Ratio; ART: Antiretroviral therapy; BMI: Body mass index; CB-NAAT: Cartridge based nucleic acid testing; Cl: Confidence interval; DM: Diabetes mellitus; EPTB: Extrapulmonary tuberculosis; IPT: Isoniazid preventive therapy; IQR: Interquartile range; IRIS: Immune reconstitution inflammatory syndrome; LPA: Line probe assay; NACO: National AIDS control organization; NNRTI: Non- nucleoside reverse transcriptase inhibitor; NRTI: Nucleoside reverse transcriptase inhibitor; PI: Protease inhibitor; PTB: Pulmonary tuberculosis; pVL: Plasma viral load; TB: Tuberculosis; VF: Virologic failure; VS: Virologic suppression; WHO: World health organization
\end{abstract}

\section{Acknowledgements}

Manisha Ghate MBBS, PhD (ICMR-National AIDS research institute, Pune, India) - edited the manuscript.

Gaurav Arun Joshi MBA (Accenture Strategy Consulting) - helped in preparing figures and tables.

\section{Authors' contributions}

$A D, U M, M K, C G$ and CS conceived of the study and drafted the manuscript. $\mathrm{KN}, \mathrm{MM}, \mathrm{RG}, \mathrm{SK}, \mathrm{NR}$ and $\mathrm{MD}$ participated in its design and coordination, read, revised and approved the final manuscript. All authors read and approved the final manuscript.

\section{Funding}

This research received no specific grant from any funding agency in the public, commercial or not-for-profit sectors.

\section{Availability of data and materials}

The datasets used and/or analyzed during the current study available from the corresponding author on reasonable request.

\section{Ethics approval and consent to participate}

This research was approved by the Institutional review board (IRB) of all 3 hospitals (Poona hospital and Research Centre, Ruby Hall Clinic and Noble Hospital, Pune, India) in which the study was conducted. Administrative permissions required to access the raw data were also granted by IRB. It was a retrospective cohort study and hence patients consent to participate was not required.

\section{Consent for publication}

Not applicable.

\section{Competing interests}

The authors declare that they have no competing interests.

\section{Author details}

${ }^{1}$ Department of Medicine, Ruby Hall Clinic, Pune, Maharashtra, India. 2Department of Medicine, Poona Hospital and Research Centre, Pune, Maharashtra, India. ${ }^{3}$ Department of Medicine, Noble hospital, Pune, Maharashtra, India. ${ }^{4}$ Department of Biostatistics, Precision Diagnostics and Biosciences, Pune, Maharashtra, India. ${ }^{5}$ Department of Pathology, Precision Diagnostics and Biosciences, Pune, Maharashtra, India. ${ }^{6}$ Department of Microbiology, Poona Hospital and Research Centre, Pune, Maharashtra, India. ${ }^{7}$ Department of Dermatology, Ashwini Sahakari Rugnalaya and Research Centre, Solapur, Maharashtra, India. ${ }^{8}$ Department of Medicine, Apex hospital, Kolhapur, Maharashtra, India. ${ }^{9}$ Department of Microbiology, Infectious Disease Clinic, Dhule, Maharashtra, India. 


\section{Received: 16 November 2018 Accepted: 6 August 2019} Published online: 13 August 2019

\section{References}

1. World Health Organization. Global Tuberculosis Report 2017.

2. Revised National Tuberculosis Control program. National Strategic plan for Tuberculosis elimination 2017-2025. https://tbcindia.gov.in/WriteReadData/ NSP\%20Draft\%2020.02.2017\%201.pdf.

3. India TB report 2018. Revised National Tuberculosis Control program. Annual Status report. https://tbcindia.gov.in/showfile.php?lid=3314.

4. Van Rie A, Westreich D, Sanne I. Tuberculosis in patients receiving antiretroviral treatment: incidence, risk factors, and prevention strategies. J Acquir Immune Defic Syndr. 2011;56:349-55.

5. Lawn SD, Harries AD, Williams BG, Chaisson RE, Losina E, De Cock KM, Wood R. Antiretroviral therapy and the control of HIV-associated tuberculosis. Will ART do it? Int J Tuberc Lung Dis. 2011;15:571-81.

6. Suthar AB, Lawn SD, Amo J, Getahun H, Dye C, Sculier D, et al. Antiretroviral therapy for prevention of tuberculosis in adults with HIV: a systematic review and meta-analysis. PLoS Med. 2012;9:e1001270.

7. National AIDS control organization. Annual Report NACO 2016-17. http:// naco.gov.in/sites/default/files/NACO\%20ANNUAL\%20REPORT\%202016-17. pdf.

8. World Health Organization. Guidelines for intensified tuberculosis case finding and isoniazid preventive therapy for people living with HIV in resource constrained settings. 2011

9. Pretorius C, Menzies NA, Chindelevitch L, Cohen T, Cori A, Eaton JW, et al. The potential effects of changing HIV treatment policy on tuberculosis outcomes in South Africa: results from three tuberculosis-HIV transmission models. AIDS. 2014;28(Suppl 1):S25-34.

10. Lawn SD, Badri M, Wood R. Tuberculosis among HIV-infected patients receiving HAART: long term incidence and risk factors in a south African cohort. AIDS. 2005;19:2109-16.

11. Lawn SD, Myer L, Edwards D, Bekker LG, Wood R. Short-term and long-term risk of tuberculosis associated with CD4 cell recovery during antiretroviral therapy in South Africa. AIDS. 2009;23:1717-25.

12. Moore D, Liechty C, Ekwaru P, Were W, Mwima G, Solberg P, et al. Prevalence, incidence and mortality associated with tuberculosis in HIV -infected patients initiating antiretroviral therapy in rural Uganda. AIDS. 2007;21:713-9.

13. Dembele M, Saleri N, Carvalho AC, Saouadogo T, Hien AD, Zabsonre I, et al. Incidence of tuberculosis after HAART initiation in a cohort of HIV-positive patients in Burkina Faso. Int J Tuberc Lung Dis. 2010;14:318-23.

14. Etard JF, Diouf A, De Beaudrap P, Akoi K, Ngom-Gueye NF, Ndiaye I, et al. Short and long-term incidence of tuberculosis and CD4-cell count dynamic on HAART in Senegal. Open AIDS J. 2009;3:63-70.

15. Choun K, Thai S, Pe R, Lorent N, Lynen L, van Griensven J. Incidence and risk factors for tuberculosis in HIV-infected patients while on antiretroviral treatment in Cambodia. Trans R Soc Trop Med Hyg. 2013;107(4):235-42.

16. Hermans SM, Kiragga AN, Schaefer P, Kambugu A, Hoepelman Al, Manabe YC. Incident tuberculosis during antiretroviral therapy contributes to suboptimal immune reconstitution in a large urban HIV clinic in sub -Saharan Africa. PLoS One. 2010;5:e10527.

17. Houlihan CF, Mutevedzi PC, Lessells RJ, Cooke GS, Tanser FC, Newell ML. The tuberculosis challenge in a rural south African HIV programme. BMC Infect Dis. 2010;10:23.

18. del Amo J, Moreno S, Bucher HC, Furrer H, Logan R, Sterne J, et al. Impact of antiretroviral therapy on tuberculosis incidence among HIV positive patients in high income countries. Clin Infect Dis. 2012:54(9):1364-72.

19. Naidoo K, Karim QA, Bhushan A, Naidoo K, Yende-Zuma N, McHunu PK, et al. High rates of tuberculosis in patients accessing HAART in rural South Africa. J Acquir Immune Defic Syndr. 2014;65(4):438-46.

20. Gupta A, Wood R, Kaplan R, Bekker LG, Lawn SD. Tuberculosis incidence rates during 8 years of follow up of an antiretroviral treatment cohort in South Africa: comparison with rates in the community. PLoS One. 2012;7(3):e34156.

21. Nicholas S, Sabapathy K, Ferreyra C, Varaine F, Pujades-Rodriguez M Incidence of tuberculosis in HIV-infected patients before and after starting combined antiretroviral therapy in 8 sub-Saharan African HIV programs. J Acquir Immune Defic Syndr. 2011;57:311-8.
22. Liu E, Makubi A, Drain P, Spiegelman D, Sando D, Li N, Chalamilla G Tuberculosis incidence rate and risk factors among HIV - infected adults with access to antiretroviral therapy. AIDS. 2015;29(11):1391-9.

23. Ahmed A, Mekonnen D, Shiferaw AM, Belayneh F, Yenit MK. Incidence and determinants of tuberculosis infection among adult patients with HIV attending HIV care in north-East Ethiopia: a retrospective cohort study. BMJ Open. 2018;8(2):e016961.

24. Gunda D, Maganga S, Nkandala I, Kilonzo S, Mpondo B, Shao E, et al. Prevalence and risk factors of active TB among adult HIV patients receiving ART in northwestern Tanzania: a retrospective cohort study. Can J Infect Dis Med Microbiol. 2018;2018:1346104

25. Padmapriyadarsini C, Bhavani PK, Sekar L, Anandhachitra SM, Poornagangadevi $\mathrm{N}$, et al. Effectiveness of symptom screening and incidence of tuberculosis among adult and children living with HIV infection in India. Natl Med J India. 2016;29(6):321-5.

26. Rajasekaran S, Raja K, Jeyaseelan L, Vijilat S, Priya K, Mohan K, et al. Post -HAART tuberculosis in adults and adolescents with HIV in India: incidence, clinical and immunological profile. Indian J Tuberc. 2009;56(2):69-76.

27. Arinaminpathy $N$, Batra D, Khaparde S, Vualnam T, Maheshwari N, Sharma L, et al. The number of privately treated tuberculosis cases in India: estimation from drug sales data. Lancet Infect Dis. 2016;16(11):1255-60.

28. World Health Organization (WHO): Guidelines and policy briefs on HIV. https://apps.who.int/iris/bitstream/handle/10665/277395/WHO-CDS-HIV-1 8.51-eng.pdf?ua=1.

29. National AIDS control organization (NACO): Policy and Guidelines. http:// naco.gov.in/sites/default/files/NACO\%20-\%20National\%20Technical\%2 OGuidelines\%20on\%20ART_October\%202018\%20\%281\%29.pdf.

30. Getahun H, Kittikraisak W, Heilig CM, et al. Development of a standardized screening rule for tuberculosis in people living with HIV in resource-constrained settings: individual participant data meta-analysis of observational studies. PLoS Med. 2011;8(1):e1000391. https://doi.org/10.1371/journal.pmed.1000391.

31. Global Tuberculosis Control. Surveillance, Planning, Financing. WHO Report; 2002

32. Nahid P, Dorman S, Alipanah N, Barry P, Brozek J, Cattamanchi A, Chaisson $L$, et al. Official American Thoracic Society/Centers for Disease Control and Prevention/Infectious Diseases Society of America clinical practice guidelines: treatment of drug-susceptible tuberculosis. Clin Infect Dis. 2016;63(7):853-67.

33. WHO Treatment Guidelines for Drug-Resistant Tuberculosis, 2016 Update. https://apps.who.int/iris/bitstream/handle/10665/250125/9789241549639eng.pdf; jsessionid=F54F64B85BBC9736E8183D419B93E01A? sequence=1.

34. Sreeramareddy CT, Qin ZZ, Satyanarayana S, Pai M. Delays in diagnosis and treatment of pulmonary tuberculosis in India: a systematic review. Int J Tuberc Lung Dis. 2014;18:255-66.

35. McDowell A, Pai M. Treatment as diagnosis and diagnosis as treatment: empirical management of presumptive tuberculosis in India. Int J Tuberc Lung Dis. 2016;20:536-43.

36. Udwadia ZF, Pinto LM, Uplekar MW. Tuberculosis management by private practitioners in Mumbai, India: has anything changed in two decades? PLoS One. 2010;5(8):e12023.

37. Styblo K. The relationship between the risk of tuberculosis infection and the risk of developing infectious tuberculosis. Bull Int Union Tuberc Lung Dis. 1985;60:117-9.

38. Lawn SD, Myer L, Bekker LG, Wood R. Burden of tuberculosis in an antiretroviral treatment programme in sub-Saharan Africa: impact on treatment outcomes and implications for tuberculosis control. AIDS. 2006; 20(12):1605-12

39. Walker NF, Scriven J, Meintjes G, Wilkinson RJ. Immune reconstitution inflammatory syndrome in HIV infected patients. HIV AIDS (Auckl). 2015;7:49-64.

40. Oni T, Burke R, Tsekela R, Bangani N, Seldon R, Gideon H, et al. High prevalence of subclinical tuberculosis in HIV-1 infected persons without advanced immunodeficiency : implications for TB screening. Thorax. 2011; 66(8):669-73.

41. Jiang H, Yin J, Fan Y, Liu J, Zhang Z, Liu L, et al. Gender difference in advanced HIV disease and late presentation according to European consensus definitions. Sci Rep. 2015;5:14543.

42. Bock P, Jennings K, Vermaak R, Cox H, Meintjes G, Fatti G, et al. Incidence of tuberculosis among HIV-positive individuals initiating antiretroviral treatment at higher CD4 counts in the HPTN 071 (PopART) trial in South Africa. J Acquir Immune Defic Syndr. 2018;77(1):93-101.

43. Moir S, Chun TW, Fauci AS. Pathogenic mechanisms of HIV disease. Annu Rev Pathol. 2011;6:223-48 
44. Kaplan JE, Hanson DL, Jones JL, Dworkin MS. Viral load as an independent risk factor for opportunistic infections in HIV-infected adults and adolescents. AIDS. 2001;15(14):1831-6.

45. Fenner L, Atkinson A, Boulle A, Fox MP, Prozesky H, Zürcher K. HIV viral load as an independent risk factor for tuberculosis in South Africa: collaborative analysis of cohort studies. J Int AIDS Soc. 2017;20(1):21327.

46. World Health Organization. WHO guidelines on the use of CD4, Viral load and early infant diagnosis (EID) tests for initiation and monitoring of ART. http://www.who.int/hiv/amds/102_WHO_Guidelines_on_CD4_and_VL_for_ ART_Doherty.pdf.

47. National AIDS control organization. National operational guidelines for viral load testing. 2018.

48. WHO Three I's Meeting Intensified Case Finding (ICF). Isoniazid Preventive Therapy (IPT) and TB Infection Control (IC) for people living with HIV. Geneva: Report of a Joint World Health Organization HIV/aids and TB Department Meeting; 2008.

49. WHO. Programmatic update: Antiretroviral Treatment as Prevention (TASP) of HIV and TB. https://www.who.int/hiv/pub/mtct/programmatic_update_ tasp/en/.

50. Rangaka MX, Wilkinson RJ, Boulle A, Glynn JR, Fielding K, van Cutsem G, et al. Isoniazid plus antiretroviral therapy to prevent tuberculosis: a randomised double-blind, placebo-controlled trial. Lancet. 2014;384:682-90.

51. Semu M, Fenta TG, Medhin G, Assefa D. Effectiveness of isoniazid preventive therapy in reducing incidence of active tuberculosis among people living with HIV/AIDS in public health facilities of Addis Ababa, Ethiopia: a historical cohort study. BMC Infect Dis. 2017;17(1):5.

52. Khawcharoenporn T, Apisarnthanarak A, Manosuthi W, Sungkanuparph S, Mundy LM. Isoniazid preventive therapy and 4-year incidence of pulmonary tuberculosis among HIV infected Thai patients. Int J Tuberc Lung Dis. 2012; 16(3):336-41.

53. Sabasaba A, Mwambi H, Somi G, Ramadhani A, Mahande MJ. Effect of isoniazid preventive therapy on tuberculosis incidence and associated risk factors among HIV infected adults in Tanzania: a retrospective cohort study. BMC Infect Dis. 2019;19(1):62.

54. Samandari T, Agizew TB, Nyirenda S, Tedla Z, Sibanda T, Shang N, et al. 6 -month versus 36-month isoniazid preventive treatment for tuberculosis in adults with HIV infection in Botswana: a randomised, double-blind, placebo -controlled trial. Lancet. 2011;377:1588-98.

55. Swaminathan S, Menon PA, Gopalan N, Perumal V, Santhanakrishnan RK, Ramachandran $\mathrm{R}$, et al. Efficacy of a six month versus a 36 month regimen for prevention of tuberculosis in HIV infected persons in India : a randomized controlled trial. PLoS One. 2012;7(12):e47400.

56. Ghate M, Tripathy S, Gangakhedkar R, Thakar M, Bhattacharya J, Choudhury I, et al. Use of first line antiretroviral therapy from a free ART programme clinic in Pune, India: a preliminary report. Indian J Med Res. 2013;137(5):942-9.

57. Lawn SD, Bekker LG, Wood R. How effectively does HAART restore immune responses to mycobacterium tuberculosis? Implications for tuberculosis control. AIDS. 2005;19:1113-24.

58. Crampin AC, Mwaungulu JN, Mwaungulu FD, Mwafulirwa DT, Munthali K, Floyd S, et al. Recurrent TB: relapse or reinfection? The effect of HIV in a general population cohort in Malawi. AIDS. 2010;24:417-26.

59. Charalambous S, Grant AD, Moloi V, Warren R, Day JH, Van Helden P, et al. Contribution of reinfection to recurrent tuberculosis in south African gold miners. Int J Tuberc Lung Dis. 2008;12:942-8.

60. Lönnroth K, Williams BG, Cegielski P, Dye C. A consistent log-linear relationship between tuberculosis incidence and body mass index. Int J Epidemiol. 2010;39(1):149-55.

61. Kohli M, Schiller I, Dendukuri N, Dheda K, Denkinger CM, Schumacher SG, et al. Xpert ${ }^{\circledast}$ MTB/RIF assay for extrapulmonary tuberculosis and rifampicin resistance. Cochrane Database Syst Rev. 2018;2018(8):CD012768.

62. Griffith DE, Aksamit T, Brown-Elliott BA, Catanzaro A, Daley C, Gordin F, et al. An official ATS/IDSA statement: diagnosis, treatment, and prevention of nontuberculous mycobacterial diseases. Am J Respir Crit Care Med. 2007; 175(4):367-416.

\section{Publisher's Note}

Springer Nature remains neutral with regard to jurisdictional claims in published maps and institutional affiliations.

\section{Ready to submit your research? Choose BMC and benefit from:}

- fast, convenient online submission

- thorough peer review by experienced researchers in your field

- rapid publication on acceptance

- support for research data, including large and complex data types

- gold Open Access which fosters wider collaboration and increased citations

- maximum visibility for your research: over $100 \mathrm{M}$ website views per year

At BMC, research is always in progress.

Learn more biomedcentral.com/submissions 